\title{
TRADICIÓN Y CONTEXTO: EL SAINETE DE FINALES DEL SIGLO XVIII
}

Al amparo de una ya larga reflexión sobre las ideas de algunos saineteros de fines del XVIII ${ }^{1}$, quizá pueda extraer ciertas conclusiones y plantear algunas dudas de carácter más general sobre la complejidad ideológica del teatro menor de aquella época. El estudio de tales aspectos conceptuales se imbrica, además, con el análisis de cuestiones aparentemente más endoliterarias, pues los cambios ideológicos del teatro sainetesco de la segunda mitad del Siglo de las Luces representan asimismo cambios en la architextualidad $^{2}$, hasta tal punto que el sainete se redefine en esos años, influido por la alta y secular productividad del teatro entremesil, por la comedia neoclásica (la transtextualidad o trascendencia textual), y por el sistema cultural de la época ilustrada.

Dentro de la voluntad pedagógica que caracteriza el ámbito de actuación cultural del Conde de Aranda o de Floridablanca (o de Leandro Fernández de Moratín y Jovellanos, para situarnos en el plano teatral), no cabe olvidar que el teatro es concebido como escuela de costumbres. Sin duda, de acuerdo con el general y secular menosprecio teórico y crítico del sainete, raramente se le nombra en aquellos artículos, elogios, memorias, etc. con que se procura incidir, de manera ilustrada, tanto en la escena como en la sociedad españolas. Sin embargo, parece muy difícil que la permeabilidad del género entremesil (proclive a aceptar

${ }^{1}$ Desde "Ramón de la Cruz entre dos fuegos: literatura y público", $\mathrm{CuH}, 1973$, núms. 277/278, 350-360, y "Singular y plural de Juan Ignacio González del Castillo", EEB, 19 (1975), 103-115, hasta "Bases y tópicos morales de los sainetes de Ramón de la Cruz", $A L H C$, 2 (en prensa), y Los sainetes de González del Castillo en el Cádiz de finales del siglo xviii, Cátedra Adolfo de Castro-Fundación Municipal de Cultura, Cádiz (en prensa).

${ }^{2}$ Empleo la terminología de Julia Kristeva (Semeiotiké) y Gérard GeNETTE (Introduction á l'architexte). 
todos los recursos del teatro "mayor" incluso por las claves iró" nica y paródica; pensemos en Manolo o en El Muñuelo, de Ramón de la Cruz) no acogiera de buen grado aquellas novedades doctrinarias de la comedia neoclásica que pudieran resultar populares o popularizables; con la ayuda, además, de que algunos saineteros no andaban ideológicamente muy lejos del liberalismo ilustrado (así Luciano F. Comella), y de que el complejo de inferioridad de los autores de comedias de santos o de magia y de entremeses favorecía la apropiación teórica de los postulados neoclásicos, aunque luego, en la práctica, se continuara sirviendo a las preferencias más o menos (post)barrocas y (pre)románticas del pueblo.

El teatro fue, para las élites del dieciocho, escuela de costumbres... y, de un modo más o menos parecido al théatre de situations de Jean-Paul Sartre, se convirtió en tribuna de opiniones y en tribunal. La elocuencia al servicio de un sermón laico, en la línea de los discursos de los salones y de las sociedades económicas, que contrarrestara los pareceres y los "anatemas" de los sermones religiosos y de los sectores tradicionalistas de los colegios mayores y las universidades. "Hacer amable la virtud y aborrecible el vicio", había defendido Ignacio de Luzán en su Poética, y a la educación política y patriótica de los espectadores se encaminan los voluntariosos autores de tragedias, al igual que se fomentan las artes útiles con Los menestrales, de Cándido María Trigueros, o Las bodas de Camacho, de Meléndez Valdés. La crítica contemporánea (Jorge Campos, Emilio Palacios, I. A. Maravall... .) ${ }^{3}$ ha insistido sobre el tema, por si no bastara con los testimonios coetáneos. Así lo afirmó en 1773, Pablo de Olavide en una carta a Tomás Sebastián y Latre:

El designio de dar a la nación un teatro ilustrado y corregido es, en mi modo de pensar, uno de los más importantes y útiles, porque en mi concepto nada forma tanto las costumbres de un pueblo, nada ameniza más a la nobleza y a la plebe, nada inspira tanta dulzura, urbanidad y amor a la honradez como las frecuentes lecciones que se dan al público en el teatro ${ }^{4}$.

(Harina de otro costal es la capacidad de asunción, ya de la crítica neoclásica ya de los postulados ilustrados, que podían

${ }^{3}$ Véase J. A. Maravall, "La función educadora del teatro en el siglo de la Ilustración", en Estudios dedicados a Juan Peset, Valencia, 1982.

${ }^{4}$ Apud Marcelin Defourneaux, Pablo de Olavide, el afrancesado, Renacimiento, México, 1965, p. 53. 
tener los saineteros de la segunda mitad del siglo xvin: sirva como botón de muestra de la escasa aptitud para respetar aquellos principios críticos, el Hamleto de Ramón de la Cruz, especialmente si es comparado con la traducción de la obra de Shakespeare por Leandro Fernández de Moratín.)

Por tanto, y sea cual sea el grado de transitividad en cada autor, ni la voluntad pedagógica de los ilustrados - tan insistente, por ejemplo, en el campo de las censuras y de la crítica teatral en los periódicos-, ni la propia tradición del género entremesil, ni el complejo de inferioridad de los saineteros, ni en algunos casos su propia ideología permiten otra cosa que afirmar lo obvio: el influjo del sistema cultural y teatral predominante sobre el sainete, en el triple nivel de la intertextualidad, la transtextualidad y la architextualidad. Para profundizar en ello nos conviene recoger, en primer lugar, la doble función del teatro como escuela de costumbres y tribuna (con una última escena como tribunal).

Por de pronto, el interés de los intelectuales cercanos al Conde de Aranda por el teatro mayor (tragedias y comedias) - al margen del poco interés por la cultura que, según cierta historiografía actual, tuvo el rey, Carlos III - afectó indirectamente la representación de los sainetes, al menos en Madrid y en Cádiz: las numerosas disposiciones en orden a mejorar las compañías teatrales, el público y sus condiciones, y las frecuentes diligencias en pro de una indumentaria y un atrezzo adecuados ejercieron una influencia claramente positiva en los códigos no verbales del sainete; véanse los textos espectaculares de los sainetes de Ramón de la Cruz, las acotaciones de sus loas y fines de fiesta, que lo prueban. El propio escritor madrileño sabía hasta qué punto dependía su éxito de tales signos y marcas de representación:

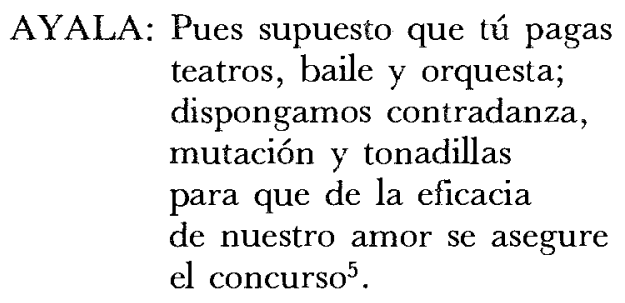

${ }^{5}$ RAMÓN DE LA CRUZ, Templo de amor y placer (fin de fiesta para el auto $E l$ cubo de la almudena), vv. 280-286, en Ten unedited works by Ramón de la Cruz, ed. E. V. Coughlin, Albatros-Hispanófila, Valencia, 1987, p. 25. 
En el campo de batalla entre ilustrados y antiilustrados se esgrimen ideas contrapuestas acerca de las nuevas costumbres; las huestes tradicionalistas (desde Forner a Hervás y Panduro) defienden la ortodoxia, con su misoneísmo y xenofobia, pero el conflicto se traslada - no sólo por la voluntad pedagógica de la elite en una sociedad semianalfabeta, también por razones de espectacularidad y hasta de simplificación ejemplificadora- de la prensa al escenario. También por este camino ideológico el sainete se benefició de la polémica entre el conservadurismo moral y la crítica ilustrada: a aquél le debe una buena parte de sus recursos cómicos lingüísticos, al añadir a los falsos latinismos de los sacristanes de los viejos entremeses, la burla xenófoba de los galicismos de petimetres y abates:

He aquí, en efecto — como escribe Jiménez Lozano ${ }^{6}$ - el oído ortodoxo, las piae aures de la vieja España, escandalizada ante las nuevas proposiciones malsonantes y sapientes haeresim y la "algarabía", o lengua que el cristiano viejo no podía entender y daba, entonces, por supuesto que era "habla de moros" o "habla de judíos": ahora "habla de herejes" es el francés.

También al tradicionalismo de los apologetas y antiilustrados deberá el sainete una buena parte de su eficacia satírica en el lenguaje verbal, el gestual y la indumentaria; al igual que la comedia neoclásica: el choque entre los viejos usos y las nuevas costumbres tiene lugar

... en el plano de la vivencia y de la cotidianeidad mucho antes, mucho más y mucho más profundamente que en el de las ideas. La Ilustración y la filosofía son ese caballero vestido de seda, oliendo a perfume y con peluca, o un abate con chapines y gorgnera a la francesa que aparecen un día ante el viejo hidalgo vestido de negro o ante los frailes mendicantes de pobre hábito y los clérigos llenos de gravedad bajo sus holapandas ${ }^{7}$.

Es así, en el teatro menor, y de manera altamente significativa: por simbolización, por metonimia, por excelencia y antonoma-

6 "La percepción castiza del ilustrado", en La Ilustración en España y Alemania, coords. R. Mate y F. Niewöhner, Anthropos, Barcelona, 1989, p. 144.

${ }^{7}$ Ibid., p. 143. 
sia. No creo, pues, caer en la exageración si, a partir de tal revitalización de su condición crítica y de su renovada permeabilidad contextual, afirmo que los rasgos architextuales del nuevo sainete han sufrido un cambio estético (y ético, modal, lingüístico, temático...) respecto al viejo entremés, es decir, a la tradición del género, acercándose - y no paradójicamente- a la prosa costumbrista. Las transformaciones sociales, por otro lado, ayudarían sin duda a explicar este acercamiento a cierta prensa periódica y a las reflexiones de los moralistas, sobre todo si tenemos en cuenta la perspectiva histórica, desde Lope de Rueda hasta Diamante e incluso Torres Villarroel, nunca tan atentos a la cotidianeidad. Así, no debe provocar extrañeza, en el plano intertextual, que tanto el cuadro de costumbres periodístico como la pintura y la ilustración costumbristas transitaran por caminos paralelos al sainete durante muchas décadas del siglo xix, hasta tipificar una imagen meridionalizadora del español y lo español castizos, algo impensable si se analizan el paso o el entremés del siglo XVII.

Hay, con todo, otras causas dignas de ser tenidas en cuenta para explicar la transformación del teatro menor a partir de Ramón de la Gruz: si comparamos el tratamiento que recibe el pueblo en los sainetes con las funciones que se le asigna en los géneros mayores, estableceremos unas diferencias que, con la evolución social y consecuente dignificación del artesanado urbano por la política ilustrada, favorecerían una mayor estima por los majos y, en general, por los protagonistas de muchas de estas piezas "menores". Lo que afectó la consideración social debió asimismo de repercutir en el teatro más popular y popularista, que se benefició de esta manera al "tener que" presentar a sus héroes sin la ridiculización caricaturizadora de los entremeses anteriores.

Si repasamos, en las antípodas de la consideración que el pueblo recibe en el sainete, las tragedias neoclásicas, lo veremos reducido a una mera función ambientadora o bien a comportamientos acordes con la minoría de edad civil, política y hasta moral que los ilustrados le atribuían, ya siguiendo - al socaire de los imperativos del tema- al legítimo poder en Numancia destruida, de Ignacio López de Ayala, ya alzándose con "furor e insolencia" en Doña María Pacheco, de Ignacio García Malo. Frente a ello, la propia existencia de una "tragedia para reír o sainete para llorar" (Manolo, de Ramón de la Cruz) puede ser interpretada como dignificación social y por ende literaria de 
todos los manolos de los barrios populares de Madrid, que únicamente en el teatro menor encuentran un reflejo amable ${ }^{8}$.

En mi opinión, hay que relacionar estas transformaciones contextuales con otras de índole textual. No sólo la renovada per meabilidad del género entremesil se enriqueció con la visualización de las nuevas ideas, por mucho que se redujeran a los arquetipos lingüísticos, gestuales o de indumentaria de los cortejos, madamas, abates, currutacos. No sólo empieza a brotar por necesidades económicas y consideraciones ético-políticas una nueva visión social --pensemos en el plebeyismo de algunos sectores de la más encumbrada aristocracia-, que toma en cuenta al pueblo, que por su lado es capaz de hacerse con el teatro entremesil. El sainete, en el plano architextual, varía en un alto grado porque amplía hasta casi el doble su extensión y supera con relativa frecuencia los quinientos versos (Las castañeras picadas, de Ramón de la Cruz, alcanza los 920); complica por tanto toda su sintaxis narrativa - la implicación de las "escenas" gana terreno al "énfasis" y a la mera yuxtaposición, pese a su utilidad para la estética costumbrista, tan estática - con un desarrollo de las anormalidades verbales y factuales mayor, gracias a la abundancia de motivos y parties; requiere de todos los actores de la compañía, en una utilización funcional de los personajes bastante parecida a la tipología de las comedias (en El baile desgraciado y el maestro Pezuña, de González del Castillo, por ejemplo, salen dieciocho actores); huye del simple esquema del burlador burlado o del burlador castigado; se sirve de todos los recursos (mobiliario, decorado...) con que la política cultural ilustrada se enfrenta también a los moralistas detractores del espectáculo teatral; se ve favorecido, en los mejores coliseos, de los avances que el teatro musical obtiene; etcétera.

En la misma dirección cabría argüir el desplazamiento de la sinonimia entre sainete y entremés en favor del primero, se esté o no de acuerdo con que el segundo término, "entremés", va cargándose de un sentido peyorativo. Contra la opinión general ${ }^{9}$,

${ }^{8}$ Lo que se acaba de afirmar no contradice sino que complementa la tarea ilustrada de "civilizar al pueblo": "la civilización había de llevarse a cabo en todos los aspectos y recovecos de la vida popular: en las ideas y las costumbres, en el trabajo y en el ocio" (J. Varela, "La idea de "pueblo" en la Ilustración española", Ins, 1988, núm. 504, p. 13).

${ }^{9}$ Véase, por ejemplo, M. F. Vilches de Frutos, "Los sainetes de Ramón de la Cruz en la tradición literaria. Sus relaciones con la Ilustración", Seg, 1984, núms. 39/40, p. 173, n. 2. 
me parece que las nuevas obras muy a menudo reciben el nombre de "sainetes nuevos" y se relega, sin que desaparezca, el uso de la palabra "entremés" a las composiciones más simples y tradicionales, en torno al bobo, al payo, al estudiante capigorrón, al fanfarrón. . . : las de Trullo, el mico, el batán, etc. Se trataría de una consecuencia de las transformaciones del género, que revelaría su conocimiento por parte de editores, autores y público.

No hay que despreciar, por supuesto, en esta compleja relación de causas y efectos que transformaron los rasgos caracterizadores del sainete en el último tercio del siglo xvin, el talento de sus cultivadores, al fin y al cabo quienes en la práctica consiguicron que este género volviera a tener una época floreciente. $Y$, por esta misma razón, conviene no prestar demasiada atención a las críticas de los ilustrados y a quienes se han acercado al teatro menor con los mismos prejuicios; o, de prestársela, conviene saber leer entre líneas, al margen de la descalificación exclusivamente moral o fruto de la jerarquización estética de las preceptivas literarias.

En un primer grado, si no queremos apelar al rechazo de quienes son totalmente contrarios al teatro (el padre Diego José de Cádiz, por ejemplo), figuran ciertos pensadores ilustrados que ponen mucho más énfasis en la utilidad que en el deleite y tiñen su visión hasta oscurecerla con sus criterios exclusivamente morales. En una de las mejores reflexiones críticas de aquella época, se señala:

Si para merecer el dictado de ingenio cómico bastara representar con viveza y naturalidad las escenas más indecentes y torpes de miserables abandonados a los más repugnantes desórdenes, la prostitución sin disfraz, como sin freno, la ojeriza con todos cuantos dan muestra de mejor crianza, o pertenecen a menos baja jerarquía, la holgazanería sustentándose con la estafa, y ejercitándose para el robo, presidiarios y rameras remedando el estilo de la tragedia, y matándose a puñaladas por las espaldas, Don Ramón de la Cruz sería acreedor sin duda a este título: los que han leído a Terencio, Molière, Moratín, etc., dirán si le merece ${ }^{10}$.

El autor de La comedia nueva, en cambio, ofrece un grado algo mayor de comprensión, pese a la habitual dureza de sus juicios literarios:

10 Abate Marchena, "Lecciones de Filosofia y Elocuencia", en Obra en prosa, Alianza, Madrid, 1985, p. 115. 
Don Rarión de la Cruz fue el único de quien puede decirse que se acercó en aquel tiempo a conocer la índole de la buena comedia; porque dedicándose particularmente a la composición de piezas en un acto, llamadas sainetes, supo sustituir en ellas, al desaliño y rudeza villanesca de nuestros antiguos entremeses, la imitación exacta y graciosa de las modernas costumbres del pueblo ${ }^{11}$.

Al margen de la distinción que establece entre "sainete" y "entremés", en la línea de lo afirmado anteriormente, desde la primera a la última frase de la cita, Leandro Fernández de Moratín pone de manifiesto la semejanza del sainete con su concepción de la comedia, y aunque proteste a renglón seguido contra la inmoralidad - "prestó al vicio (y aun a los delitos) un colorido tan halagüeño, que hizo aparecer como donaires y travesuras aquellas acciones que desaprueban el pudor y la virtud, y castigan con severidad las leyes" - , valora en Ramón de la Cruz lo que hoy tenemos en la máxima estima crítica, "un diálogo animado, gracioso y fácil',.

El tercer grado, pues, de valoración de los sainetes de Ramón de la Cruz y sus seguidores, no supone ruptura alguna respecto al positivo veredicto del mismísimo Leandro Fernández de Moratín, sino que representa la conciencia de la transformación que se ha operado en el género entremesil: "Mas como la comedia clásica no se prestaba a sus intentos, [Ramón de la Cruz] adoptó las formas del sainete, combinándolo en un drama corto, pero de bastante extensión para desarrollar en él una acción sencilla, y bosquejar un cuadro de costumbres'. Y, Agustín Durán deduce:

Así es que este género de composición en manos de Cruz apareció bajo el imperio de una intención moral, filosófica y decidida, formando, por decirlo así, el eslabón intermedio entre el entremés antiguo y la comedia verdadera y clásica ${ }^{12}$.

No es difícil ilustrar con ejemplos esta transitividad del tealio menor de las postrimerías del XVIII. De esta manera, sea o no

${ }^{11}$ Leandro Fernández de Moratín, "Discurso preliminar de las Comedias", en Nicolás y Leandro Fernández de Moratín, Obras, BAE, t. 2, p. 317.

- 12 Agustín Durán, "Discurso preliminar", Colección de los sainetes tanto impresos como inéditos de D. Ramón de la Cruz, Imprenta de Yenes, Madrid, 1843, t. 1 (apud L. Fernández de Moratín, op. cit., p. 318, nota). 
conservador el pensamiento de Ramón de la Cruz (porque la caricaturización a menudo resulta ambigua) ${ }^{13}$, en su teorización del teatro ha asimilado los conceptos neoclásicos, aparte de su natural insistencia en la necesidad de gustar al público:

MARTÍNEZ: Es una pieza alemana
en un acto reducido
que ha amplificado hasta dos
en nuestro romance el mismo
autor de La espigadera;
y aunque no sea tan festivo
su argumento, es el más tierno
y más útil que hemos visto
quizás en nuestros teatros;
pues se da a todos los hijos
doctrina para ser buenos,
dóciles, reconocidos
y obedientes a sus padres,
con un grande requisito
para que, cuando no guste,
dé a todos poco fastidio ${ }^{14}$.

La utilidad que el neoclasicismo y en general la intelectualidad ilustrada pide al teatro cómico y trágico llega, sin necesidad de pensar en la intertextualización, al teatro menor, porque no hay una teoría que se oponga a tales principios (lo que antes se denominaba el complejo de inferioridad de los saineteros, que sólo se defienden recordando a Lope de Vega y aceptando los dictados del público) y porque el sistema cultural predominante ha ido ganando batalla tras batalla, crítica y teóricamente, a los escritores de comedias de magias, dramas históricos o entreme-ses. No cabe olvidar el análisis de Jorge Campos:

El teatro de las dos últimas décadas del siglo puede considerarse teatro de la Ilustración no solamente por estas huellas de su ideario intercalado en la trama amorosa y la tradicional conformación de

${ }^{13}$ Véanse mis artículos citados en la.n. 1 y cf. M. T. VILCHÉS DF FruTOs, art. cit.: los mismos ejemplos pueden ser empleados para defender un pensamiento tradicionalista o bien una ideología ilustrada.

${ }^{14}$ RAMÓn DE LA CRUZ, "Introducción para empezar las diversiones en las noches de verano del año 1780 por las dos compañías de cómicos de Madrid', vv. 393-408, en Ten unedited..., pp. 152-153 (se refiere a El fínix de los hijos). 
las comedias, sino también por llevar a la escena, de un modo deliberado, la realización práctica de sus ideales, mostrando sus benéficos influjos y la paz y la felicidad que se deriva de ellos ${ }^{15}$.

Sea o no tradicionalista, abundan las claras exposiciones ilustradas en los sainetes de Ramón de la Gruz, o con mayor motivo ideológico en liberales como Luciano F. Comella (así, en el sainete El alcalde proyectista ${ }^{16}$ ) y Juan Ignacio González del Castillo. Manolo, que en su calidad de "tragedia para reír o sainete para llorar', quizás representaba el acercamiento a la dignidad trágica del artesano, por mucho que se hiciera en clave paródica, termina con estos versos reveladores de la preocupación del Siglo de las Luces por el ocio y el trabajo del pueblo:

MEDIODIENTE: Voy allá. ¿De qué aprovechan todos vuestros afanes, jornaleros, y pasar las semanas con miseria, si dempués los domingos o los lunes disipáis el jornal en la taberna? ${ }^{17}$

Puestos a establecer comparaciones entre las obras teatrales de la segunda mitad del siglo xviII y sus referentes sociales, no sería nada fácil establecer la inferioridad literaria e ideológica del sainete, a pesar del Diktat de su público y el secular acopio de tópicos y recursos con que se suele confeccionar: si la tragedia neoclásica pasó con más pena que gloria por los escenarios de Madrid, Sevilla, Valencia, etc. es porque, en su defensa de la aristocracia y del patriotismo solidario, no supo conectar con la realidad del espectador; poco después lo explicarán Diderot y Schiller y Goethe. Los intentos neoclásicos en materia de comedia, también los de Moratín hijo y Tomás de Iriarte, tienden a una tipificación del petimetre o la señorita malcriada que no va más allá, en cuanto a profundidad y complejidad, al que ya conocemos por los mejores sainetes coetáneos. Pero incluso la comedia sentimental, más adecuada a las inquietudes de la clase

15 Jorge Campos, Teatro y sociedad en España (1780-1820), Moneda y Crédito, Madrid, 1969, p. 37.

${ }^{16}$ Tomo la referencia de M. DI PINTo, "En defensa de Comella", Íns, 1988, núm. 504, p. 17.

17 RaMón de la CRUz, Manolo, vv. 368-372, en Sainetes, ed. F. Lafarga, Cátedra, Madrid, 1990, p. 248. 
burguesa de aquel momento, aporta un escaso ahondamiento en el campo de las ideas y del autoconocimiento de su grupo social, sin que ello suponga menospreciar el notable valor literario de $E l$ delincuente honrado, de Gaspar Melchor de Jovellanos.

En relación con la apropiación indebida del término "tragedia" por autores mayoritarios y de nula ambición artística como José Concha, Juan Antonio Ríos demuestra también hasta qué punto el predominio neoclásico afectó en los niveles más humildes del teatro de la época de Carlos III y, sobre todo, de Carlos IV. Así,

tengamos en cuenta que los autores del teatro mayoritario creaban sondeando las opiniones, gustos y necesidades de su público y en ellas influían, de una o de otra manera, los resortes manejados por los neoclásicos. Influencia que sería más activa todavía entre los propios autores. Por ello, el seguir el gusto mayoritario no implica forzosamente un alejamiento del "buen gusto", aunque a menudo implicó una adulteración relativamente consciente del mismo ${ }^{18}$.

Sus palabras valen también para el sainete.

Por otro lado, la comparación con los otros géneros del teatro y su evolución ratifica la evolución del teatro menor a partir de Ramón de la Cruz: ha habido, como he intentado probar, un desplazamiento del background (del contexto y, en consecuencia, de la lectura de la tradición), y el sainete del escritor madrileño o el de González del Castillo o el de Comella es recibido y percibido de manera distinta que el entremés de la primera mitad o de mediados del siglo xviII. A estas conclusiones, y dudas, hemos llegado también sin recurrir a la terminología de la pragmática.

Para relativizar, sin embargo, la eficacia de la voluntad pedagógica de los ilustrados, de su contagio moral y literario en la esfera del teatro menor, y de los cambios modales, temáticos y formales que tuvieron lugar en el género sainetesco, es preferible no repetir conclusiones ni volver a sembrar dudas, porque " $i$ habrá un solo sugeto, que asegure haber debido enmiendas a la enseñanza de un Entremés, de un Baile, de un Sainete?"'19 Me pa-

${ }^{18} \mathrm{~J}$. A. Ríos, "José Concha y la tragedia neoclásica", Il Confronto Lette" rario, 2 (1985), p. 113

19 Tomás de Erauso y Zabaleta, Discurso crítico sobre el origen, calidad y estado presente de las comedias de España, 1750. (Apud EMILIo Cotarelo y MorI, 
rece que, una vez más, afortunadamente, como en los viejos entremeses, el engañador salió engañado, y el deleitar se disfrazó tan sólo con algunos de los ropajes del aprovechar.

Josep Maria Sala Valldaura

Universitat de Barcelona

Bibliografía de las controversias sobre la licitud del teatro en España . . , Biblioteca $\mathrm{Na}$ cional, Madrid, 1904, p. 246.) 